\title{
Comparative Analysis of the Main Business Intelligence Solutions
}

\author{
Alexandra RUSANEANU \\ Faculty of Cybernetics, Statistics and Economic Informatics \\ Bucharest University of Economic Studies, Romania \\ rusaneanu_alexandra@yahoo.com
}

\begin{abstract}
Nowadays, Business Intelligence solutions are the main tools for analyzing and monitoring the company's performance at any organizational level. This paper presents a comparative analysis of the most powerful Business Intelligence solutions using a set of technical features such as infrastructure of the platform, development facilities, complex analysis tools, interactive dashboards and scorecards, mobile integration and complex implementation of performance management methodologies.
\end{abstract}

Keywords: Performance Management, Business Intelligence, Mobile Integration, OLAP, Scorecard

\section{1} Introduction

Performance management is a relatively new concept, but "the word performance is widely used in all fields of management. In the management control area, terms such as performance measurement (Euske, Lebas and McNair, 1993), evaluation, or appraisal (e.g. Bruns, 1992) is used. Despite the frequency of use of the word, its precise meaning is rarely explicitly defined by authors even when the main focus of the article or of the book is performance. (e.g. Baird, 1986; Richard, 1989). Often, performance is identified or equated with effectiveness and efficiency (e.g. Neely, Gregory, and Platts, 1995; Corvellec, 1994). A publication of the French Ministry of Industry equated performance with lean production, competitiveness, cost reduction, value and job creation, growth, and long-term survival of enterprises. In short, performance is one of those "suitcase words" (Bourguignon, 1995) in which everyone places the concepts that suit them, letting the context take care of the definition" [1]. Performance can be expressed as a set of complementary indicators that describes the process by which certain results are achieved. Also performance can be defined as a dynamic causal model that describes how certain actions affect future results. Performance is closely related to decision making because performance has no intrinsic value, it exists only when an individual or more use it to make decisions. If the description of perfor- mance has no impact on a system or organization then the performance has no value. Also, the description of performance is relative to the perspective from which analyzes, it can be a accounting, operational or strategic perspective.

Performance management includes activities that ensure the fulfillment of targets in an efficient and effective way. These activities are focused on achieving performance of an organization, a department, employees or even some manufacturing processes of a product or a service. Another definition of performance management extracted from a dictionary of management considers that performance is "a process by which organizations align their resources, systems and employees to strategic objectives and priorities."[2] This approach is typical for strategy-based management.

\section{Performance Management}

The goal of performance management is to ensure the fulfillment of the objectives set by the organization whether they are at strategic, operational or individual level. In order to achieve this goal must be followed a basic set of steps which are valid regardless of the implementation level: organization, subsystems, processes and so on. Some of these activities includes: [3]

a. reviewing organizational goals and their correlation with performance units;

b. elaborate the desired results; 
c. ensure the existence of correlation between the results on a certain domain and the results of the organization;

d. prioritize the domain's desired results;

e. finding a first level of evaluating the results and identifying the achieved level;

f. identifying more specific measures for the first level of evaluation, if it is necessary;

g. define standards for evaluating the results;

h. create a performance plan that includes the expectations, measures and standards;

i. create a performance review.

The instruments of performance management need to be used by an organization, department, team or person in a way that the performance achieved to be developed and improved. There is no formula for designing and developing the instruments of performance management to ensure successful implementation and results. However, there are some factors [4] that influence the success:

a. defining the position and the priorities in performance management;

b. selecting an instrument that is correlated with the structure, culture and strategy of the organization, also the instrument must consolidate the strategy regarding performance and future directions of the company;

c. each instrument has a significant role in communication within the organization.

In the article "Rediscovering performance management: systems, learning and integration" performance management "has been divided into three levels: strategic, operational and individual performance management". [5] Individual performance management is an integrated system for improving the performance of employees at all levels and requires the definition of a performance plan that leads employees to achieve desired results but also that leads the corporation to achieve their objectives. An important feature is that performance can be measured. For this level exists different ways of gathering information and also there are certain indicators that synthesize information and expose it in an aggregate manner for an easier way of tracking the fulfillment of the objectives. Some of these indicators include: training days per employee, cost on training, number of complains, actual time taken to fill a position, etc. There are numerous indicators and they can be divided into many categories like: workforce planning, equal employment opportunities or recruitment

"Performance management at operational level is linked to operational management, as its focus is the achievement of departmental or group objectives. Although it is aligned with corporate strategy, its focus is more functional. Scorecards and Dashboards are some of the key tools used."[5] Operational management is strongly related to accounting, because the operational performance is evaluated using efficiency and effectiveness and the easiest modality to do this is by using financial indicators like solvability, liquidity, profitability or other financial ratios. "The rise of business intelligence software products over the last ten years had a profound impact on how companies manage their operational performance. Enterprise resource planning software (SAP, Oracle, etc.), combined with business intelligence software (Business Objects, Hyperion, Cognos, etc.) enabled companies to reach new levels of data integration, by making the data gathering and reporting process more streamlined."[5]

Strategic performance management is the highest level of performance management. It focuses on the organizational level objectives. The most significant processes are related to organizational strategy, how to establish it and how to execute in order to have conclusive results. Some popular methodologies for this type of performance management include: Balanced Scorecards, Performance Prism, Baldrige Award, and European Foundation for Quality Management Excellence Model (EFQM). [5]

\section{Performance Management and Business Intelligence Tools}

There is a strong correlation between software programs for performance management and improved business and organizational results. Direct benefits of using these systems 
are:

- increase sales, reduce costs, reduce delaying of the projects;

- improving learning and development;

- facilitate and optimize the decision making process;

- facilitate communication and collaboration.

Business Intelligence concept involves raw data that needs to be condensed from different data sources and then transformed in information. Performance Management concept uses this information and transpose it into an intuitive decision making format. "To differentiate BI from PM, performance management can be viewed as deploying the power of BI, but the two are inseparable. Think of PM as an application of BI. PM adds context and direction for BI."'[6]

Business Intelligence gives companies the ability to access, analyze and use their data to make business decisions. This system is used both for daily operational activities and long- term strategic decisions. There are two areas of interest where BI is necessary: Business planning and Business execution. Business planning includes objectives such as increase revenue or reduces costs. Performance Management supports Business Intelligence in providing special dashboards that highlights how the company's performance align with business goals and provides actionable metrics in order to guide the company toward performance. Business execution refers to tactical and operational activities. The difference between the two is time. If tactical refers to business activities over a certain period of time, days, weeks, operational refers to daily business activities. Table 1 "compares traditional BI with BI used for BPM. It demonstrates how BPM forms the underpinnings for many of the BI developments we have outlined. Specifically, BPM helps BI cause operational decision making to become more proactive and timely, and support a wide range of business users.'[7].

Table 1. BI comparison [7]

\begin{tabular}{|c|c|c|}
\hline Category & Traditional BI & BI for BPM \\
\hline Implementation & Departmental & Enterprise-wide \\
\hline Focus & Historical & Timely, right-time, or real-time \\
\hline Orientation & Reactive & Proactive \\
\hline Output & Analyses & Recommendations and actions \\
\hline Process & Open-ended & Key performance indicators (KPIs) \\
Measures & Metrics & Personalized \\
\hline Views & Generic & Dashboards and scorecards \\
\hline Visuals & Tables, charts and reports & Built-in \\
\hline Collaboration & Informal & Exceptions \\
\hline Interaction & Pull (ad hoc queries) & Structured and unstructured \\
\hline Analysis & Trends & Structured \\
\hline Data & &
\end{tabular}

Regarding Business Intelligence tools, Gartner has an annually research paper named Magic Quadrant for Business Intelligence Platforms. This study focuses on three areas of interest:

- integration, which deals with collaborating data,

- information delivery, where reporting is a major aspect and

- analysis, which involves predictive mod- eling and processing. [8]

This is this year's edition "Magic Quadrant" that presents the current state of the BI solutions market. The most powerful companies IBM, SAP, SAS, MicroStrategy and Microsoft remain on leading position. A novelty is Tableau Software, because for the first time is on a leading position, last year was in Challengers category. 


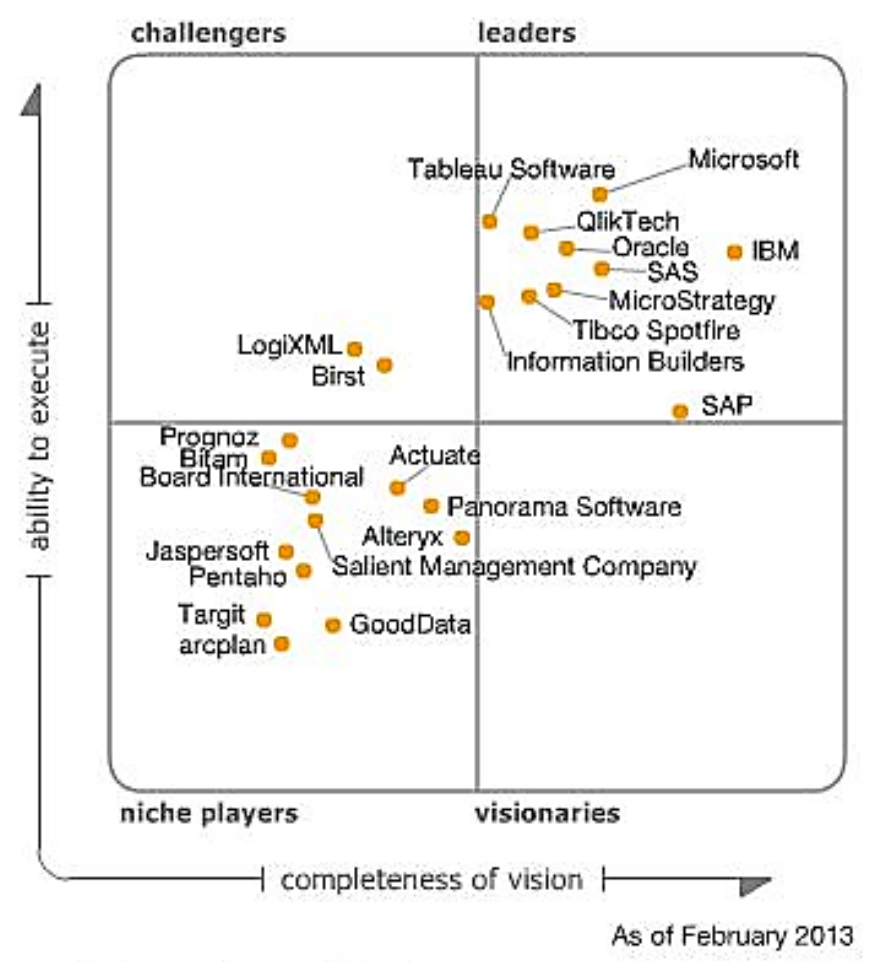

Source: Gartner (February 2013)

Fig. 1. Magic Quadrant for Business Intelligence and Analytics Platforms

\section{Case Study: Comparative Analysis of the most powerful BI platforms}

The analysis was made for the most important Business Intelligence Platforms found by Gartner: IBM Cognos 8, Oracle BI Foundation Suite 11g, SAS 9 Enterprise Intelligence Platform, SAP Business Object BI Platform, MicroStrategy 9.3, QlikView, WebFOCUS 8 and Microsoft SQL Server. These platforms were evaluated using 16 technical capabilities that were divided into 5 categories: Infrastructure \& Development, Analysis, Scorecards, Data Visualization and Mobile Integration. Nowadays, mobile integration has become a mandatory requirement in business environment because provides managers the opportunity to be acquainted with the company's progress and make decisions quickly and efficiently wherever they are. Thus, an important share in this analysis is mobile integration. These are the 16 capabilities with a short description:

\section{Infrastructure \& Development}

a. BI integrated infrastructure: common security, administration, query engine;

b. Development: development tools and SDK for developing applications or tools; c. Metadata: the ability to store and reuse metadata objects across different users and applications.

II. Analysis

a. OLAP: the ability to make fast queries, sophisticated sorting, hierarchies, interrow calculations, ROLAP calculations;

b. Data Mining Services: create predictive modeling using complex algorithms like clustering, optimization, forecasting or classification;

c. Statistical Modeling: analyze data using statistical models like: Average Deviation, Beta Distribution or Fisher Transformation.

\section{Scorecards}

a. Six Sigma: support for this process management methodology;

b. Balanced Scorecards: support for strategic management methodology;

c. KPIs: support for Key Performance Indicators for measuring the performance of the company.

\section{Data Visualization}

a. Reports: the ability to create interactive reports with complex settings from multiple sources, operational and analytical. 
b. Dashboards: create interactive reports using a web-based interface for publishing key indicators. This interface uses gauges, traffic lights or dials to highlight information and make it easier to understand.

c. Microsoft Office Integration: the ability to integrate Microsoft Excel: export and import data, render reports, dashboards and scorecards.

V. Mobile Integration

a. Data Visualization \& Exploration: interact with touch-optimized graphs, grids and also explore and modify the data;

b. Analysis: interact with dashboards, scorecards, OLAP analysis;

c. Alerts: receive alerts when key indicators have been changed or when some actions need manager approval;

d. Offline Analysis \& Data Exploration: in- teract with reports, dashboards, graphs, grid and data exploration even when you are not connected with the BI server.

Methodology: In order to compare the BI platforms, for each characteristic is given a score from 0 to 100 as follows:

0 - Functionality not provided.

25 - Functionality provided by another application from the same vendor or third - party.

50 - Basic functionality provided, requires customization with development tools.

75 - Functionality provided with some basic options.

100 - Functionality provided with a wide range of options and customization tools.

The following table shows the scores of the Business Intelligence Platforms for each characteristic:

Table 2. Scores for Business Intelligence Platforms

\begin{tabular}{|c|c|c|c|c|c|c|c|c|}
\hline $\begin{array}{c}\text { Platforms / } \\
\text { Characteristics }\end{array}$ & 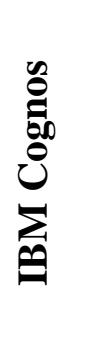 & 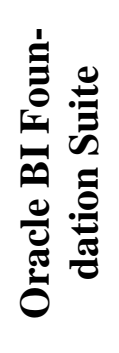 & 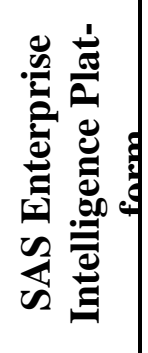 & 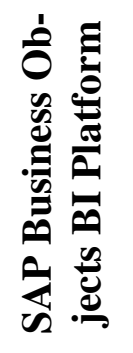 & 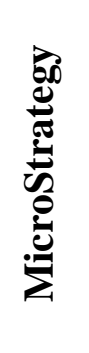 & 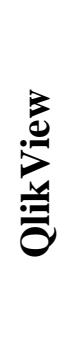 & $\begin{array}{l}0 \\
0 \\
0 \\
0 \\
0 \\
0 \\
0\end{array}$ & 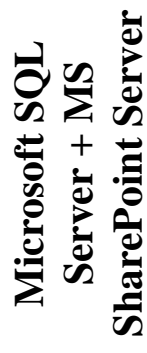 \\
\hline BI Infrastructure & 100 & 75 & 75 & 100 & 100 & 75 & 75 & 50 \\
\hline Development & 100 & 75 & 75 & 75 & 100 & 75 & 100 & 75 \\
\hline Metadata & 75 & 100 & 100 & 75 & 100 & 25 & 50 & 50 \\
\hline OLAP & 75 & 100 & 100 & 75 & 75 & 50 & 50 & 100 \\
\hline Data Mining & 25 & 100 & 100 & 75 & 75 & 0 & 75 & 75 \\
\hline Statistics & 50 & 25 & 100 & 75 & 75 & 0 & 75 & 50 \\
\hline Predictive Modelling & 25 & 25 & 100 & 75 & 75 & 0 & 75 & 75 \\
\hline Six Sigma & 0 & 75 & 75 & 25 & 100 & 50 & 75 & 25 \\
\hline Balanced Scorecard & 100 & 75 & 75 & 25 & 100 & 50 & 75 & 50 \\
\hline KPIs & 100 & 75 & 50 & 25 & 100 & 50 & 75 & 75 \\
\hline Reports & 100 & 100 & 75 & 75 & 100 & 75 & 75 & 75 \\
\hline Dashboards & 100 & 75 & 75 & 75 & 100 & 100 & 75 & 75 \\
\hline $\begin{array}{l}\text { MS Office Integra- } \\
\text { tion }\end{array}$ & 75 & 75 & 75 & 75 & 75 & 50 & 75 & 100 \\
\hline $\begin{array}{l}\text { Mobile Data Visuali- } \\
\text { zation }\end{array}$ & 75 & 75 & 75 & 100 & 75 & 75 & 100 & 75 \\
\hline Mobile Analysis & 75 & 100 & 75 & 75 & 75 & 75 & 100 & 50 \\
\hline Alerts & 0 & 50 & 0 & 75 & 75 & 75 & 75 & 0 \\
\hline Offline mode & 75 & 75 & 0 & 75 & 75 & 50 & 0 & 0 \\
\hline
\end{tabular}


1. Infrastructure \& Development: On this category the platform with the highest average score is MicroStrategy 9.3.1. Its integrated Intelligence Server supports "the full range of BI applications - from workgroup and departmental, to enterprise-wide BI through a unified metadata and a single inte- grated server running on Windows ${ }^{\circledR}$, UNIX ${ }^{\circledR}$, or Linux ${ }^{\circledR}$."[9] The platforms with the lowest score are Microsoft and QlikView. Microsoft has two independent products for fulfilling the Business Intelligence architecture: SQL Server and SharePoint.

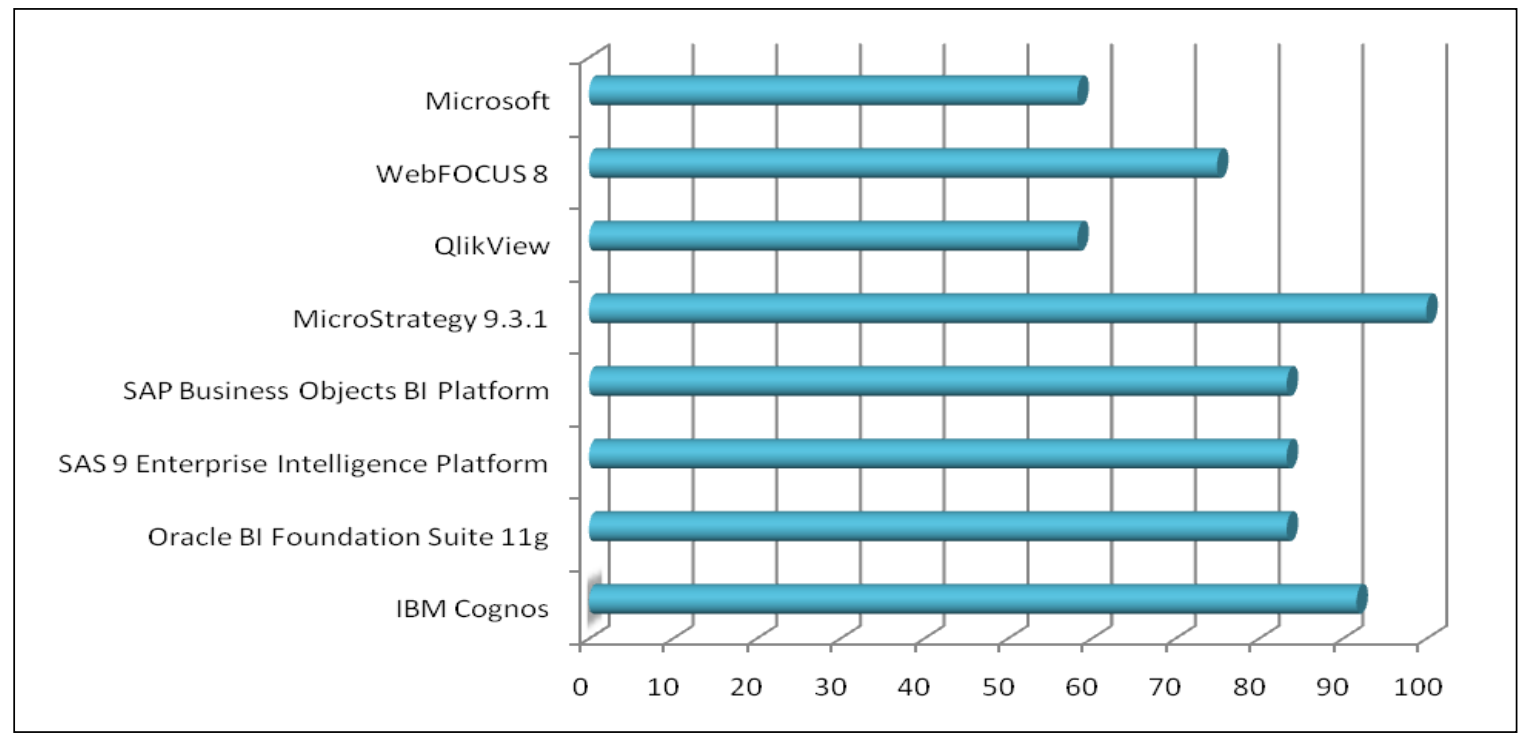

Fig. 2. Infrastructure and development

2. Analysis: The platform with the highest score is SAS Enterprise. It has the most powerful OLAP Engines, In-Memory BI and Adhoc analysis. Also, SAS offers a various statistical and predictive modeling functions based on complex algorithms. QlikView has the lowest score because it doesn't have an OLAP Engine for processing data; it only offers the possibility to connect to databases or analysis systems like SAP or Oracle.

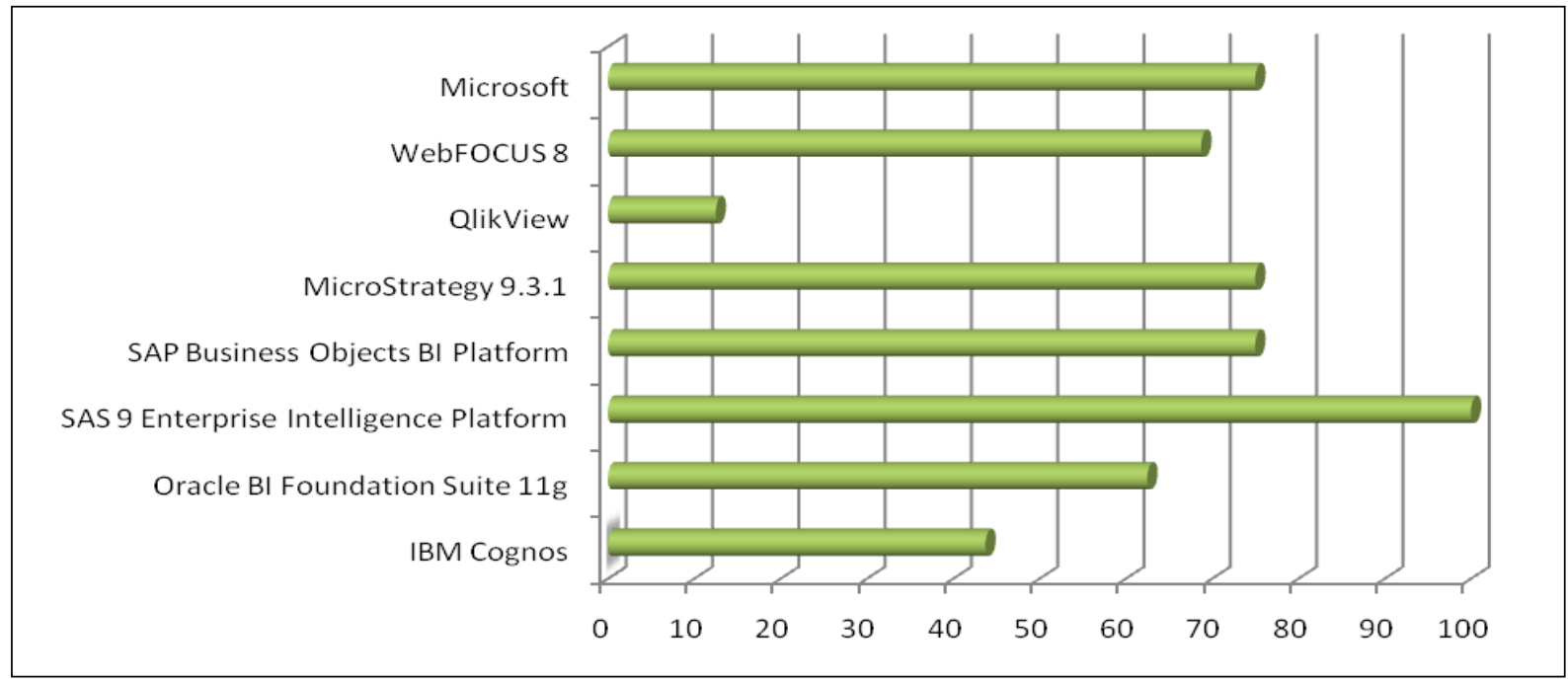

Fig. 3. Analysis

3. Scorecards: MicroStrategy has the most interactive and intuitive Performance and
Strategy Management data visualization and offers complete support for most perfor- 
mance management methodologies. On the other hand, SAP has the lowest score because offers another software for this type of management and is not included in Business Objects BI platform. Strategy Management
EPM is a complete solution for monitoring, analyzing and improving business performance using KPIs. These two solutions must be integrated and requires material and human resources.

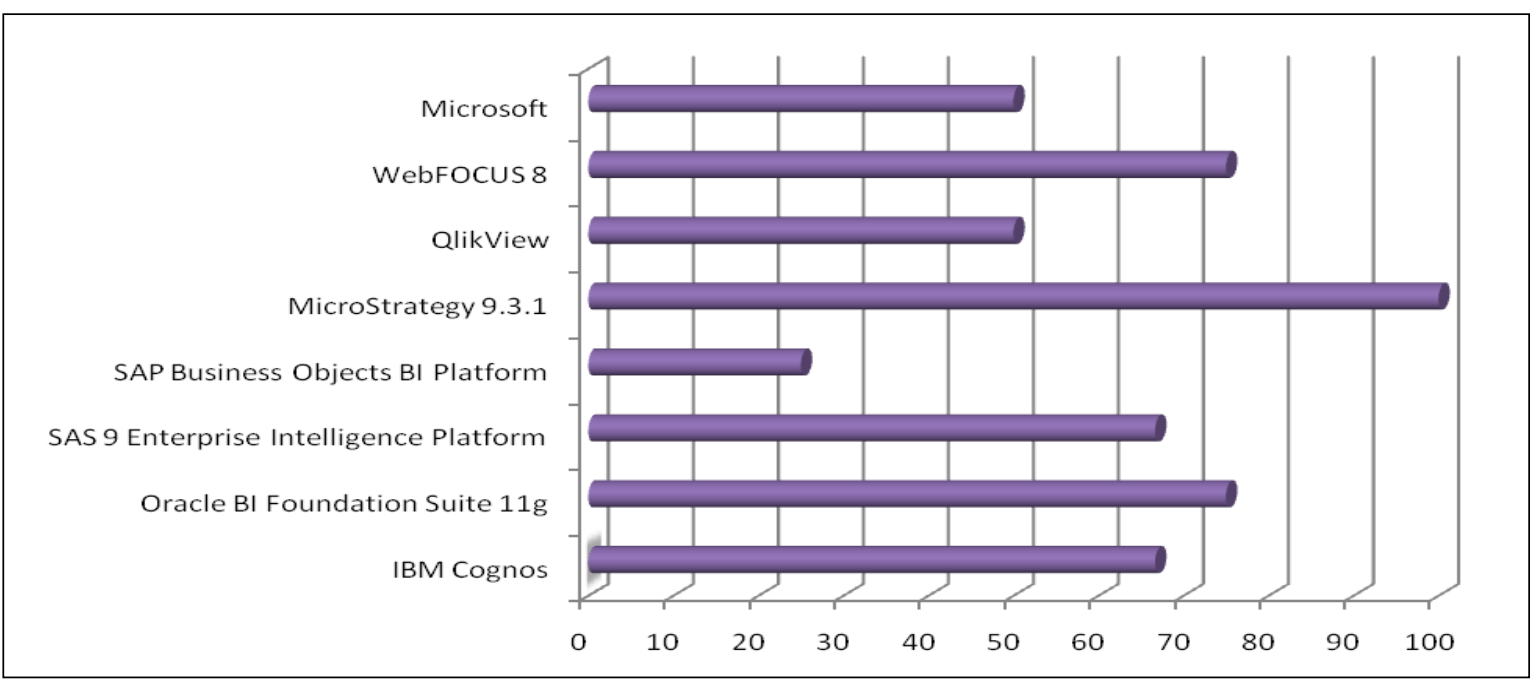

Fig. 4. Scorecards

4. Data Visualization: In this category the most advanced solutions are MicroStrategy and IBM Cognos. These two solutions have fully integrated reporting services, easy to understand and with an intuitive interactivity. Also, the Microsoft Office tool integrated in these solutions has advanced functionalities such as the ability to create new reports in Microsoft Office or deploy dashboards, scorecards and OLAP in an Excel client. On the other hand, QlikView has only options for exportation and importation of documents but has strong dashboard services.

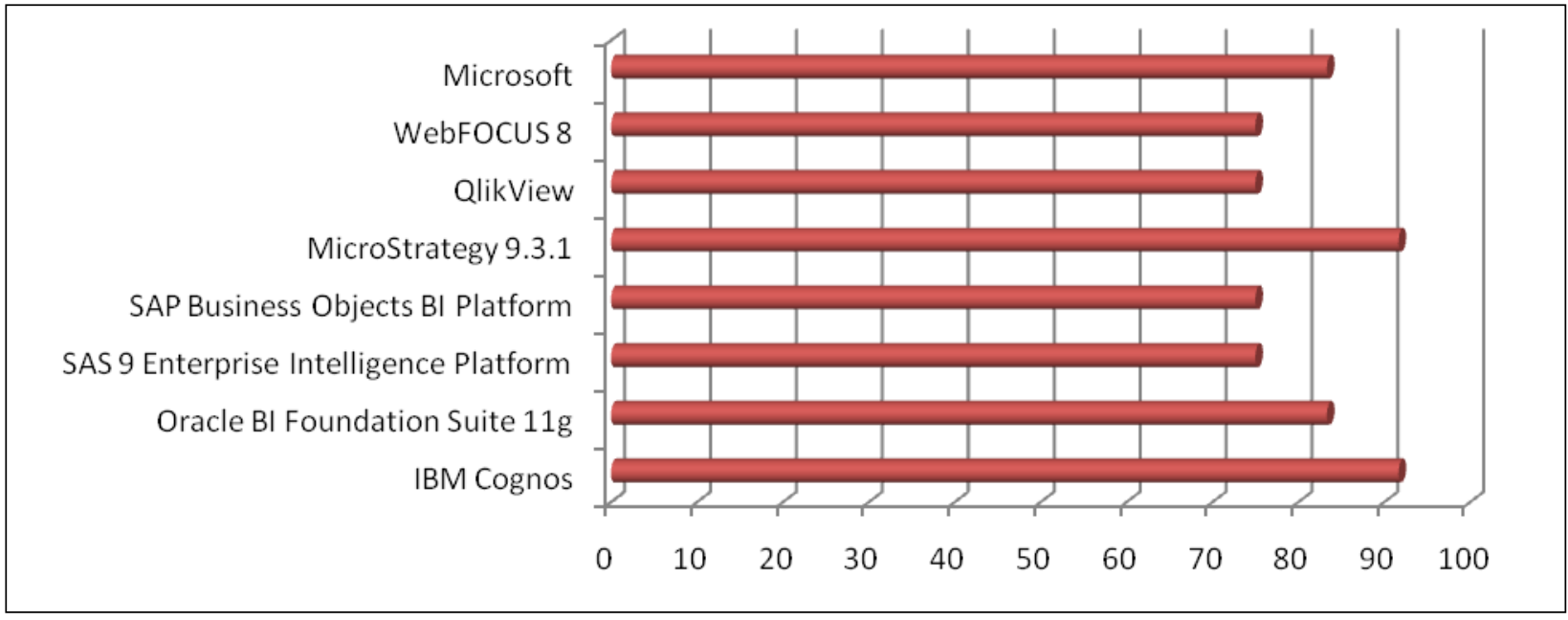

Fig. 5. Data Visualization

5. Mobile Integration: An important criterion for this category was the integration of mobile services in the BI platform. The platforms with a complete set of functionalities are SAP Business Objects Platform,
MicroStrategy and Oracle BI Suite. These three have touch-optimized graphs, dashboards and a full interaction with data, alert services and offline mode. 


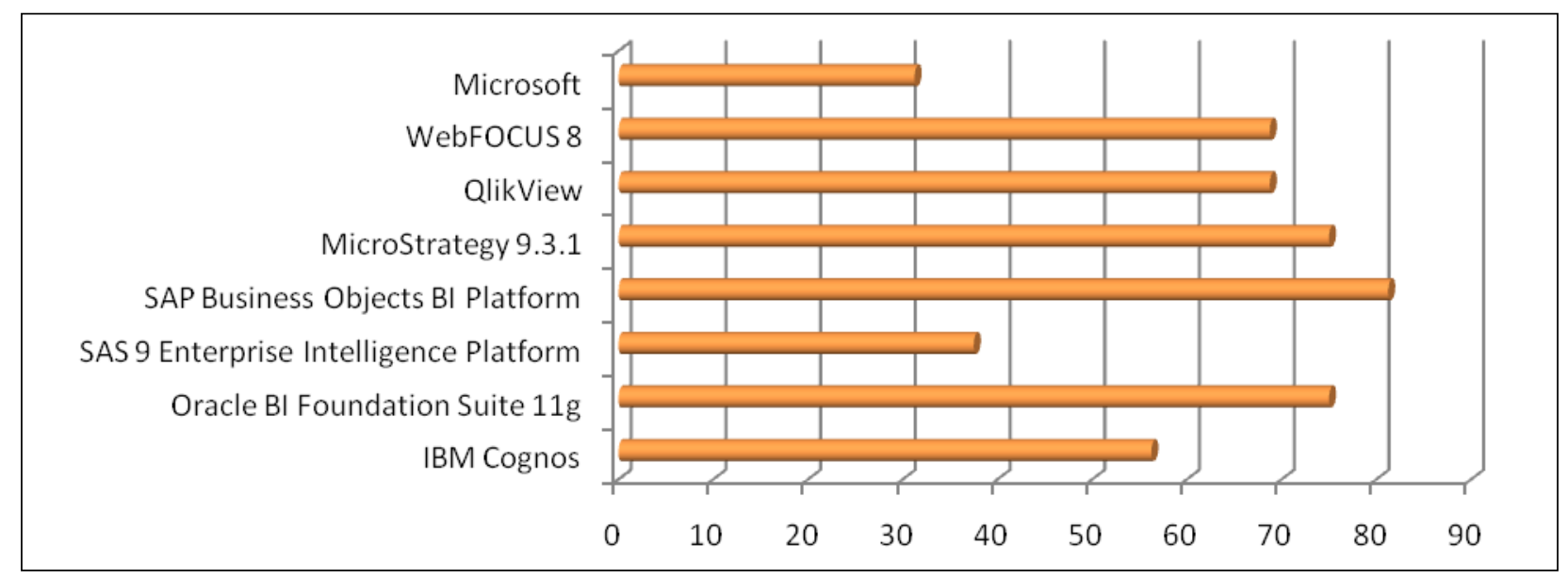

Fig 6. Mobile Integration

6. Overall Score

To achieve the global score were introduced weights that reflect the importance of each category, as in Table 3.

Table 3. Global score weights

\begin{tabular}{|l|c|}
\hline \multicolumn{1}{|c|}{ Category } & Weight \\
\hline Infrastructure \& Development & $26.67 \%$ \\
\hline Analysis & $33.33 \%$ \\
\hline Scorecards & $13.33 \%$ \\
\hline Data Visualization & $20.00 \%$ \\
\hline Mobile Integration & $6.67 \%$ \\
\hline
\end{tabular}

After applying these weights the global scores are presented in Table 4.

Table 4. Global Scores

\begin{tabular}{|c|c|}
\hline BI Platforms & Overall Score \\
\hline MicroStrategy 9.3.1. & 88.33 \\
\hline SAS Enterprise Intelligence Platform & 81.94 \\
\hline Oracle BI Foundation Suite & 74.72 \\
\hline WebFocus (Information Builders) & 72.50 \\
\hline SAP Business Objects BI Platform & 70.97 \\
\hline IBM Cognos & 70.00 \\
\hline $\begin{array}{c}\text { Microsoft SQL Server + MS SharePoint } \\
\text { Server }\end{array}$ & 65.97 \\
\hline QlikView & 45.97 \\
\hline
\end{tabular}

The table shows that the platform with the highest score is MicroStrategy 9.3.1 with a score of 88.33. This means that most of this platform's functionalities are provided with an average range of options and customization tools. Also, the following platforms, SAS Enterprise Intelligence and Oracle BI Foundation Suite, provide the same characteristics as the first placed. Platforms that have scores between 50 and 75 are characterized by an average range of features offered that need to be customized using programming tools. Thus, companies that implement these solutions will have to invest in financial and human capital for the implementation of these platforms or the company will bear the cost of implementation provided by the vendor. 


\section{Conclusions}

The paper presents a comparative analysis of the most powerful Business Intelligence solutions based on a set of characteristics that reflects the main structure of a BI platform. After a detailed review of the concepts of performance management and its importance as a part of a BI solution are presented the results of Gartner research and also the subject of the paper, the comparative analysis of the Bi platforms selected after the Gartner study. This analysis was designed using information found on websites, brochures, presentation papers and online broadcasts provided by the vendors.

\section{References}

[1] M. Lebas and K. Euske "A conceptual and operational delineation of performance" in Business performance measurement: theory and practice, Cambridge University Press, 2002.

[2] Glossary "Make sense of business-speak" available at: http://mystrategicplan.com/resources/sect ion/glossary/

[3] NHS Institute for Innovation and Improvement (2010), Performance management, available at: http://www.institute.nhs.uk/quality_and_ service_improvement_tools/ quality_and_service_improvement_tools/perfo rmance_management.html

[4] C. McNamara "Performance Management: Overall Goal and Basic Steps" available at: http://managementhelp.org/performance management/goals-and-steps.htm

[5] A. Brudan "Rediscovering performance management: systems, learning and integration" in Measuring Business Excellence, vol. 14, issue 1, 2010.

[6] http://www.information-management. com/news /1051320-1.html

[7] C. Ballard, C. White, S. McDonald, J. Myllymaki, S. McDowell, O. Goerlich and A. Neroda "Business Performance Management ... Meets Business Intelligence" available at: http://www.redbooks.ibm.com/

[8] The KPI Institute "Performance Management in 2012", available at: http://www.smartkpis.com/premium/prod ucts/performance-managementpublications/performance-managementin-2012-106.html

[9] http://www.microstrategy.com/software/ products/intelligence-server/

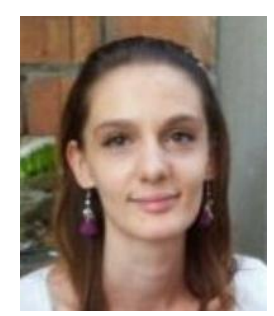

Alexandra RUSANEANU has graduated the Faculty of Economics in 2010 and Economic Informatics Master in 2012. She is a PhD student at Faculty of Cybernetics, Statistics and Economic Informatics. She works as Application Developer at a multinational company. Her research interests include Business Intelligence solutions. 